\title{
Factors Influencing Condom Use Among Sexually Transmitted Infection Clinic Patients in Montego Bay, Jamaica
}

\author{
Obinna N. Nnedu ${ }^{1}$, Staci McCorvey ${ }^{2}$, Sheila Campbell-Forrester ${ }^{3}$, Janice Chang ${ }^{4}$, \\ Hamisu M. Salihu ${ }^{5}$ and Pauline E. Jolly ${ }^{*}, 6$ \\ ${ }^{I}$ Division of Allergy and Infectious Diseases, Department of Medicine, University of Washington, Seattle, Washington, \\ USA \\ ${ }^{2}$ Veterans Administration Hospital, Palo Alto, California, USA \\ ${ }^{3}$ Ministry of Health, Kingston, Jamaica, West Indies \\ ${ }^{4}$ Western Regional Health Authority, Ministry of Health, Montego Bay, Jamaica, West Indies \\ ${ }^{5}$ Center for Research and Evaluation, Lawton and Rhea Chiles Center for Healthy Mothers and Babies, University of \\ South Florida, Tampa, Florida, USA \\ ${ }^{6}$ Department of Epidemiology, School of Public Health, University of Alabama at Birmingham, USA
}

\begin{abstract}
The use of condoms can reduce the risk of sexually transmitted infections (STIs) including the human immunodeficiency virus (HIV) infection. We conducted this study to determine factors that impact condom use among patients attending an STI clinic in Montego Bay, Jamaica. A questionnaire containing sections on socio-demographic characteristics, knowledge of STIs and HIV, preventive measures for STI/HIV transmission and sexual practices including condom use was administered to 212 participants. Using logistic regression, we determined the relationship between the different factors and condom use during the last sexual episode. Approximately $43 \%$ of study participants reported condom use during the last sexual episode. Employment $(\mathrm{OR}=2.2 ; 95 \% \mathrm{CI}=1.1-4.1)$ and greater knowledge of STIs ( $\mathrm{OR}=1.9,95 \% \mathrm{CI}=1.02-3.6)$ were associated with increased likelihood of condom use during the last sexual episode. Having multiple sexual partners was associated with decreased likelihood to report condom use $(\mathrm{OR}=0.3,95 \% \mathrm{CI}=0.1$ $0.9)$. Also, persons belonging to a religious organization were less likely to report condom use $(\mathrm{OR}=0.5,95 \% \mathrm{CI}=0.2-0.9)$. The results of this study can be used in formulating effective strategies to increase condom use in Montego Bay. This would decrease the transmission of STIs and HIV.
\end{abstract}

Keywords: Condom, STI, HIV, AIDS, prevention.

\section{INTRODUCTION}

Jamaica is located in the Caribbean and has a population of approximately 2.6 million people [1]. According to the UNAIDS, at the end of 2005, the prevalence of HIV/AIDS was $1.5 \%$ among adults aged 15-49 years in Jamaica [2]. This was up from an estimated adult prevalence of $1.2 \%$ at the end of 2001 and $0.7 \%$ at the end of 1999 [3, 4]. In 2005, HIV was the fourth leading cause of death for all men and women in Jamaica [5]. The main mode of HIV transmission in Jamaica is through heterosexual sexual intercourse [6]. Approximately one of every two persons who reported with AIDS had a history of a sexually transmitted infection (STI) as a risk factor [5]. A number of behavioral, economic and socio-cultural factors that drive the spread of the HIV epidemic in Jamaica have been identified [7]. These include multiple sexual partners, early sexual activity, inconsistency

*Address correspondence to this author at the Department of Epidemiology at the School of Public Health, University of Alabama at Birmingham, RPHB 217. 1665 Univ Blvd, Birmingham, AL 35294, USA; Tel: 205-9341823; Fax: 205-975-3329; E-mail: jollyp@uab.edu between knowledge and behavior regarding HIV prevention, and inconsistent condom use.

Many studies have shown that condoms can prevent the transmission of sexually transmitted infections (STIs) [8-10]. A review of multiple studies reported that consistent condom use during sexual intercourse reduced HIV incidence by $80 \%$ [9]. Meta-analysis of several studies showed that male latex condoms are effective in reducing HIV transmission by $85 \%$ [10]. Hence condom use should be a strong focus in the ongoing battle to control the rising prevalence of HIV and STIs.

The National HIV/STI Control program (NHCP) was set up by the Jamaican government in response to the AIDS pandemic [5]. The purpose of the NHCP is to provide surveillance and strategies for control of HIV and STIs. One of the NHCP's main control strategies is condom social marketing [5]. However, the rates of HIV/AIDS and other STIs continue to increase. This suggests that individuals are still engaging in risky sexual behavior and that more work needs to be done to determine factors that influence condom use. 
This paper describes a study that investigated factors associated with condom use in Montego Bay, a city with a population of about 89,000 and known as the tourism capital of Jamaica. Montego Bay is the capital of the parish of St. James which is located in the northwestern region of the island. The parish has the highest prevalence rate of AIDS cases $(992 / 100,000)$ in Jamaica [5]. This prevalence rate is more than twice the national prevalence rate of 439/100,000. The parish of St. James also had the highest HIV seropositive rate (5.778) in STI clinic attendees in the country in 2005 [5]. The economy of Jamaica is largely dependent on tourism as its main income earner and the high influx of tourists into Montego Bay each year may explain this high prevalence. A thorough understanding of the attitudes toward sex and safe sex practices of the people in this parish will be useful in controlling the incidence and prevalence of HIV/AIDS and other STIs. Also, understanding the barriers to condom use is an important step toward encouraging safer sexual practices.

\section{MATERIALS AND METHODOLOGY}

Our study was conducted at a health center in Montego Bay that provides STI and other services for the parish of St. James. Approval for the study was obtained from the Institutional Review Board at the University of Alabama at Birmingham, the Advisory Panel of Ethics and MedicoLegal Affairs in the Ministry of Health, Kingston, Jamaica and the Western Regional Health Authority, Jamaica. Study participants were recruited from patients attending the STI clinic. The patients were told of the study and asked if they were interested in participating. Those who showed interest were asked to read an informed consent form and to ask questions. After all questions were answered, they were asked to sign the informed consent form indicating their agreement to participate. A pre-tested questionnaire that included questions on demographic factors, knowledge of STIs and preventive measures taken, knowledge of HIV transmission, sexual history and practices including condom use was administered to each participant. Questions on demographic factors included age, gender, marital status, level of education, formal employment and whether participants belonged to a religious group.

Regarding knowledge of STIs, participants were asked to name all of the STIs that they knew. A knowledge score was developed in which participants were assigned one point for each STI named. However, if participants did not mention HIV/AIDS they were given a score of zero regardless of how many other STIs they mentioned. We did this to give added weight to HIV/AIDS which is the most important STI since it is fatal and not yet curable. We used the median score of 3 to compare participants with a score higher than 3 to those with a score of 3 or less. Our dependent variable of interest was condom use during the last sexual episode. We also assessed participants' knowledge of how HIV is spread by developing a score system. Participants were given a score of one point for every correct answer regarding method of HIV transmission that they gave and a score of zero for each wrong answer. Participants with a score greater than the median score of 1 for this scale were compared to those with a score less than or equal to 1. A similar score system was used to determine participants' knowledge of methods for preventing HIV infection. Participants were asked to select answers from a list of possible ways (some true, some false) that HIV can be prevented. Each correct choice was given one point and one point was subtracted for each incorrect answer. The correct options were: having only one faithful partner; using condoms all the time; abstaining completely from sex and not sharing injection needles. The incorrect options were: having a good diet; avoiding public toilets; avoid touching a person with AIDS; avoid sharing food with a person with AIDS; avoid being bitten by a mosquito; and avoid touching the corpse of someone who died from AIDS. The median score for the group was 2 and participants with a score greater than 2 were compared to those with a score of 2 or less in terms of condom use during the last sexual episode.

Questions pertaining to the participant's sexual experiences and practices and condom use included whether the participant had multiple partners, discussed AIDS with his or her partner, discussed condom use with his or her partner, carried condoms with him/her at all times, had ever experienced condom breakage during sexual intercourse, ever felt pressured to have sex without a condom, used condoms regularly and had ever met a community peer educator (CPE).

We entered the data in Microsoft Excel and then exported them into the SAS software package for statistical analysis. We generated $2 \times 2$ contingency tables to obtain crude odds ratio estimates of association between the various sociodemographic factors, knowledge scales and sexual practices and condom use during the last sexual episode. Adjusted estimates that measured the independent association between the various potential predictors of condom use were obtained from a logistic regression model. Model fit was assessed by means of the $-2 \log$ likelihood ratio test. All tests of hypothesis were two-tailed with a type 1 error rate set at $5 \%$.

\section{RESULTS}

Table 1 describes the demographic characteristics and condom use at last sexual episode for the study population. The average age of the study group was 29 years. Majority of the participants were females $(74.5 \%)$ and majority $(67.2 \%)$ had received a secondary level of education. About half of the participants $(51.4 \%)$ reported that they were employed. Approximately $43 \%$ of participants $(47 \%$ of males and $41 \%$ of females) reported using condoms during their last sexual encounter.

Table 2 shows the relationships between the demographic characteristics and condom use at last sexual episode for the study group. Odds ratio (OR) estimates in this table are unadjusted. Marital status, employment and membership in a religious organization were significantly associated with condom use at the last sexual episode. Participants who were single were $50 \%$ less likely to have used condoms during the last sexual episode compared to those who were married $(\mathrm{OR}=0.5,95 \% \mathrm{CI}=0.3-0.8)$. Also, participants who were employed were 2 times as likely to have used condoms during last sexual episode compared to those who were unemployed $(\mathrm{OR}=2.0,95 \% \mathrm{CI}=1.1-3.3)$. Participants who belonged to a religious organization were $40 \%$ less likely to have used condoms during their last sexual episode compared to those who did not belong to a religious organization $(\mathrm{OR}=0.6,95 \% \mathrm{CI}=0.3-0.99)$. 
Table 1. Demographic Characteristics of Study Population

\begin{tabular}{|l|c|}
\hline \multicolumn{1}{|c|}{ Variable } & Number (\%) \\
\hline \hline Age group (years) & $19(9.0)$ \\
$10-19$ & $100(47.1)$ \\
$20-29$ & $93(43.9)$ \\
30 and above & \\
\hline Gender & $158(74.5)$ \\
Female & $54(25.5)$ \\
Male & \\
\hline Marital status & $86(41.2)$ \\
Married & $123(58.8)$ \\
Single & \\
\hline Education & $35(18.5)$ \\
Primary/None & $127(67.2)$ \\
Secondary education & $27(14.3)$ \\
Beyond secondary education & \\
\hline Employed & $103(48.6)$ \\
No & $109(51.4)$ \\
Yes & \\
\hline Belong to a religious organization & $67(31.8)$ \\
No & $144(68.2)$ \\
Yes & $120(57.4)$ \\
\hline Condom use during last sexual episode & $89(42.6)$ \\
No & \\
Yes & \\
\hline
\end{tabular}

Unadjusted ORs for the relationship between the different knowledge scores and condom use at last sexual episode are presented in Table 3. STI knowledge score was the only score that was significantly associated with condom use. Participants with a STI knowledge score above the median were twice as likely to have used a condom during their last sexual episode compared to those with a lower score $(\mathrm{OR}=2.1,95 \% \mathrm{CI}=1.2-3.7)$.

The relationships between sexual practices including condom use and condom use at last sexual episode are presented in Table 4. Participants who said that they carried condoms with them at all times were twice as likely to report condom use during the last sexual episode compared to those who did not carry condoms $(\mathrm{OR}=1.8,95 \% \mathrm{CI}=1.01-3.4)$. Also participants who said that they used condoms regularly were 3.5 times as likely to report condom use during the last sexual episode compared to those who did not use condoms regularly; $(\mathrm{OR}=3.5,95 \% \mathrm{CI}=1.3-9.2)$.

Fig. (1) shows the results of our logistic regression analysis. All of the factors listed in the figure were included in the adjusted model. We found that participants who were employed were twice as likely to have used a condom during their last sexual episode compared to unemployed participants $(\mathrm{OR}=2.3$, 95\% CI=1.2-4.5). Also, those with a high STI knowledge score $(>3)$ were twice as likely to report condom use during their last sexual encounter compared to those with a lower STI knowledge score $(\mathrm{OR}=2.0,95 \% \mathrm{CI}=1.03-3.8)$. There was a significant relationship between number of partners and

Table 2. Association Between Demographic Factors and Condom Use During Last Sexual Episode

\begin{tabular}{|c|c|c|c|c|}
\hline Variable & $\begin{array}{l}\text { No Condom Use at Last Episode (\%) } \\
\qquad \mathbf{N}=120\end{array}$ & $\begin{array}{l}\text { Condom Use at Last Episode (\%) } \\
\qquad \mathrm{N}=89\end{array}$ & Crude OR (95\% CI) & P-Value \\
\hline $\begin{array}{l}\text { Age group (years) } \\
10-19 \\
20-29 \\
30 \text { and above }\end{array}$ & $\begin{array}{c}8.3 \\
44.2 \\
47.5\end{array}$ & $\begin{array}{l}10.1 \\
51.7 \\
38.2\end{array}$ & $\begin{array}{c}1.0 \\
1.0(0.4-2.6) \\
0.7(0.2-1.8)\end{array}$ & $\begin{array}{l}0.9 \\
0.4\end{array}$ \\
\hline $\begin{array}{l}\text { Gender } \\
\text { Female } \\
\text { Male }\end{array}$ & $\begin{array}{l}76.7 \\
23.3\end{array}$ & $\begin{array}{l}71.9 \\
28.1\end{array}$ & $\begin{array}{c}1.0 \\
1.3(0.7-2.4)\end{array}$ & 0.4 \\
\hline $\begin{array}{l}\text { Marital status } \\
\text { Married } \\
\text { Single }\end{array}$ & $\begin{array}{l}32.8 \\
67.2\end{array}$ & $\begin{array}{l}50.6 \\
49.4\end{array}$ & $\begin{array}{c}1.0 \\
0.5(0.3-0.8)\end{array}$ & $0.01 *$ \\
\hline $\begin{array}{l}\text { Education } \\
\text { Primary/None } \\
\text { Secondary } \\
\text { Tertiary }\end{array}$ & $\begin{array}{l}17.8 \\
68.2 \\
14.0\end{array}$ & $\begin{array}{l}18.8 \\
66.2 \\
15.0\end{array}$ & $\begin{array}{c}1.0 \\
0.9(0.4-2.0) \\
1.0(0.4-3.0)\end{array}$ & $\begin{array}{l}0.8 \\
1.0\end{array}$ \\
\hline $\begin{array}{l}\text { Belong to a religious org. } \\
\text { No } \\
\text { Yes }\end{array}$ & $\begin{array}{l}26.7 \\
73.3\end{array}$ & $\begin{array}{l}39.8 \\
60.2\end{array}$ & $\begin{array}{c}1.0 \\
0.6(0.3-0.99)\end{array}$ & $0.04 *$ \\
\hline $\begin{array}{l}\text { Alcohol consumption } \\
\text { Never } \\
\text { Everyday } \\
\text { Once a week } \\
\text { Twice/month }\end{array}$ & $\begin{array}{c}64.7 \\
4.3 \\
18.1 \\
12.9\end{array}$ & $\begin{array}{c}62.1 \\
3.4 \\
10.3 \\
24.1\end{array}$ & $\begin{array}{c}1.0 \\
0.8(0.2-3.6) \\
0.6(0.2-1.4) \\
1.9(0.9-4.1)\end{array}$ & $\begin{array}{c}0.8 \\
0.2 \\
0.08\end{array}$ \\
\hline
\end{tabular}

*Significant at $\mathrm{p}<0.05$.

$\mathrm{OR}=$ Odds ratio $\mathrm{CI}=$ Confidence interval . 
Table 3. Association Between Knowledge About STI/HIV and Condom Use During Last Sexual Episode

\begin{tabular}{|c|c|c|c|c|}
\hline Variable & $\begin{array}{l}\text { No Condom Use at Last Episode (\%) } \\
\qquad \mathbf{N}=\mathbf{1 2 0}\end{array}$ & $\begin{array}{l}\text { Condom Use at Last Episode (\%) } \\
\qquad \mathrm{N}=89\end{array}$ & Crude OR (95\% CI) & P-Value \\
\hline $\begin{array}{l}\text { STI knowledge score } \\
3 \text { or less } \\
>3\end{array}$ & $\begin{array}{l}72.5 \\
27.5\end{array}$ & $\begin{array}{l}56.2 \\
43.8\end{array}$ & $\begin{array}{c}1.0 \\
2.1(1.2-3.7)\end{array}$ & $0.01 *$ \\
\hline $\begin{array}{l}\text { HIV transmission knowledge score } \\
1 \text { or less } \\
>1\end{array}$ & $\begin{array}{l}56.3 \\
43.7\end{array}$ & $\begin{array}{l}60.2 \\
39.8\end{array}$ & $\begin{array}{c}1.0 \\
0.8(0.5-1.5)\end{array}$ & 0.6 \\
\hline $\begin{array}{l}\text { HIV prevention score } \\
2 \text { or less } \\
>2\end{array}$ & $\begin{array}{c}91.3 \\
8.7\end{array}$ & $\begin{array}{c}92.9 \\
7.1\end{array}$ & $\begin{array}{c}1.0 \\
0.8(0.3-2.3)\end{array}$ & 0.7 \\
\hline
\end{tabular}

*Significant at $\mathrm{p}<0.05$.

$\mathrm{OR}=$ Odds ratio $; \mathrm{CI}=$ Confidence interval .

condom use during last sexual episode. Participants who reported having sex with multiple partners were $70 \%$ less likely to have used a condom during their last sexual episode compared to those who did not report having multiple partners $(\mathrm{OR}=0.3,95 \% \mathrm{CI}=0.1-0.8)$. Finally, participants who reported that they belonged to a religious organization were $50 \%$ less likely to have used a condom during their last sexual encounter compared to those who did not belong to a religious organization $(\mathrm{OR}=0.5,95 \% \mathrm{CI}=0.2-0.9)$.

\section{DISCUSSION}

An analysis of the potential effect of an expanded global HIV prevention program showed that up to 29 million new
HIV infections could be prevented by 2010 [11]. Most HIV/AIDS prevention programs in Jamaica strongly promote condom use [5]. As a result, condom distribution in Jamaica increased from an estimated 2 million per year in the mid1980's to about 9 million in 1993 [12]. A paper published in 2001 suggested that the proportion of men aged 15-24 reporting consistent condom use in Jamaica was 22\% [13]. Another paper published in 1998 found that the proportion of men reporting condom use during the last sexual intercourse with a regular partner was $47 \%$ and with a non-regular partner was 77 [14]. Among women, the proportion using condoms was $41 \%$ with a regular partner and $73 \%$ with a non-regular partner [14]. This survey also found that while "ever use" and

Table 4. Association Between Sexual Practices and Condom Use During Last Sexual Episode

\begin{tabular}{|c|c|c|c|c|}
\hline Variable & $\begin{array}{l}\text { No Condom Use at Last Sexual } \\
\text { Episode }(\%) \quad \mathbf{N}=120\end{array}$ & $\begin{array}{c}\text { Condom Use at Last Sexual } \\
\text { Episode }(\%) \quad N=89\end{array}$ & $\begin{array}{c}\text { Crude OR } \\
(95 \% \text { CI })\end{array}$ & P-Value \\
\hline $\begin{array}{l}\text { Multiple partners } \\
\text { No } \\
\text { Yes }\end{array}$ & $\begin{array}{l}79.2 \\
20.8 \\
\end{array}$ & $\begin{array}{l}87.5 \\
12.5\end{array}$ & $\begin{array}{c}1.0 \\
0.5(0.2-1.2)\end{array}$ & 0.1 \\
\hline $\begin{array}{l}\text { Discuss AIDS with partner } \\
\text { No } \\
\text { Yes }\end{array}$ & $\begin{array}{l}32.5 \\
67.5\end{array}$ & $\begin{array}{l}25.8 \\
74.2\end{array}$ & $\begin{array}{c}1.0 \\
1.4(0.8-2.5)\end{array}$ & 0.3 \\
\hline $\begin{array}{l}\text { Discuss condom use with partner } \\
\text { No } \\
\text { Yes }\end{array}$ & $\begin{array}{l}12.7 \\
87.3\end{array}$ & $\begin{array}{c}6.7 \\
93.3\end{array}$ & $\begin{array}{c}1.0 \\
2.0(0.8-5.4)\end{array}$ & 0.2 \\
\hline $\begin{array}{l}\text { Carry condoms at all times } \\
\text { No } \\
\text { Yes }\end{array}$ & $\begin{array}{l}75.8 \\
24.2\end{array}$ & $\begin{array}{l}62.9 \\
37.1\end{array}$ & $\begin{array}{c}1.0 \\
1.8(1.01-3.4)\end{array}$ & $0.04 *$ \\
\hline $\begin{array}{l}\text { Ever experienced condom breakage } \\
\text { No } \\
\text { Yes }\end{array}$ & $\begin{array}{l}43.6 \\
56.4\end{array}$ & $\begin{array}{l}31.5 \\
68.5\end{array}$ & $\begin{array}{c}1.0 \\
1.7(0.9-3.0)\end{array}$ & 0.1 \\
\hline $\begin{array}{l}\text { Ever pressured to have sex without condom } \\
\text { No } \\
\text { Yes }\end{array}$ & $\begin{array}{l}74.4 \\
25.6\end{array}$ & $\begin{array}{l}75.9 \\
24.1\end{array}$ & $\begin{array}{c}1.0 \\
0.9(0.5-1.8)\end{array}$ & 0.8 \\
\hline $\begin{array}{l}\text { Do you use condoms regularly } \\
\text { No } \\
\text { Yes }\end{array}$ & $\begin{array}{l}45.9 \\
54.1 \\
\end{array}$ & $\begin{array}{l}19.4 \\
80.6\end{array}$ & $\begin{array}{c}1.0 \\
3.5(1.3-9.2) \\
\end{array}$ & $0.01 *$ \\
\hline $\begin{array}{l}\text { Ever met a Community Peer Educator } \\
\text { No } \\
\text { Yes }\end{array}$ & $\begin{array}{l}52.9 \\
47.1\end{array}$ & $\begin{array}{l}53.9 \\
46.1\end{array}$ & $\begin{array}{c}1.0 \\
1.0(0.6-1.7)\end{array}$ & 0.9 \\
\hline
\end{tabular}

$*$ Significant at $\mathrm{p}<0.05$.

$\mathrm{OR}=$ Odds ratio $; \mathrm{CI}=$ Confidence interval . 


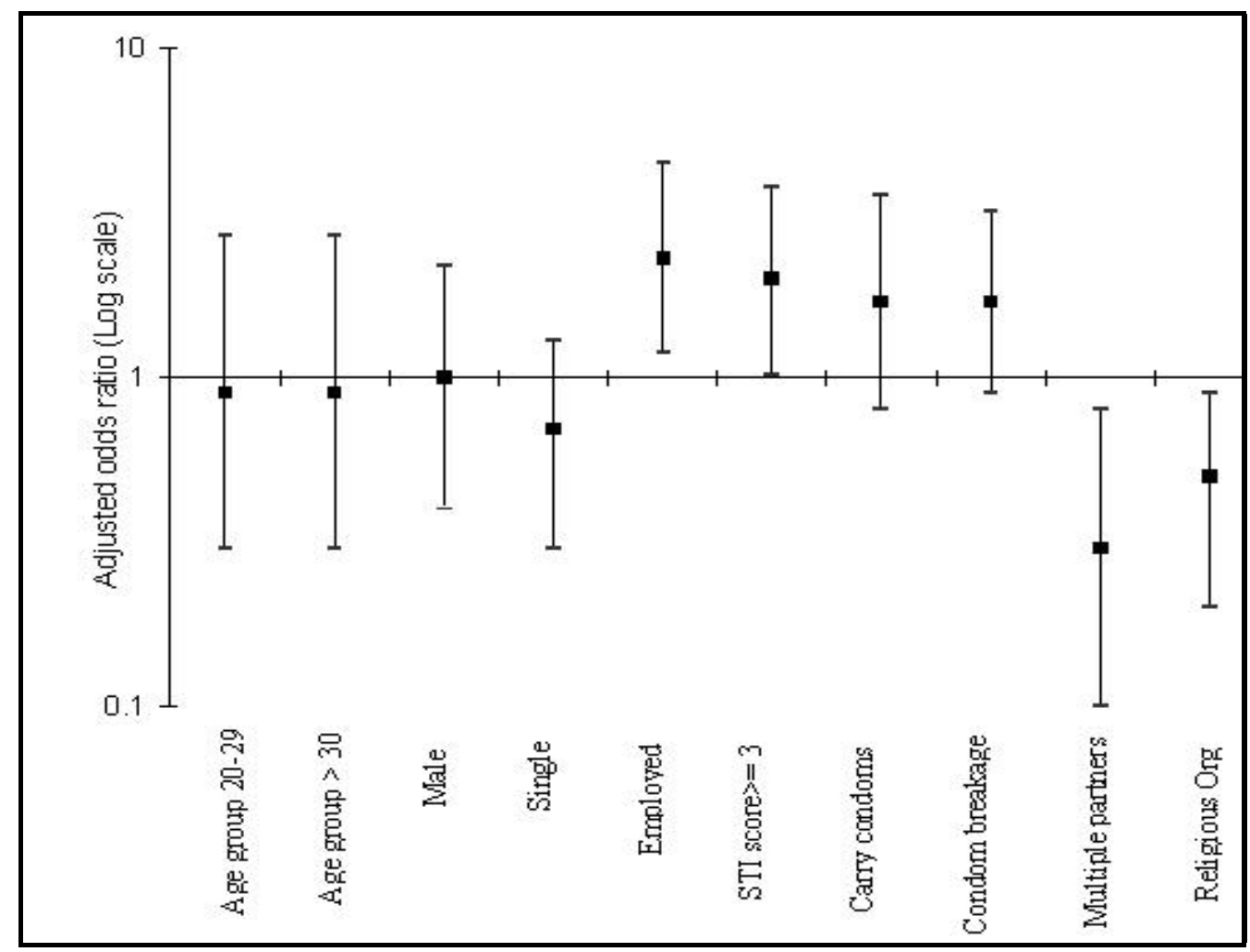

Fig. (1). Logistic analysis model for determinants of condom use at last sexual episode. Referent categories include age group 10-19, female gender, married marital status, no employment, STI knowledge score of $\leq 3$, does not carry condoms, never experienced condom breakage, does not have sex with multiple partners, and does not belong to a religious organization. Employed participants $(\mathrm{OR}=2.3,95 \% \mathrm{CI}=1.2-4.5)$ and those with high STI knowledge score $(\mathrm{OR}=2.0,95 \% \mathrm{CI}=1.03-3.8)$ were significantly more likely to have used a condom at last sexual episode. Those with multiple partners $(\mathrm{OR}=0.3,95 \% \mathrm{CI}=0.1-0.8)$ and those who belonged to a religious organization $(\mathrm{OR}=0.5,95 \% \mathrm{CI}=0.2-0.9)$ were less likely to report condom use at last sexual episode.

"episodic use" of condoms was relatively high in Jamaica, consistent condom use was less common. Our study shows that only $47 \%$ of men and $41 \%$ of women in Montego Bay reported condom use at the last sexual episode. This information suggests that despite the proven efficacy of condoms at preventing HIV/AIDS and other STIs [8-10], and the efforts over the years to increase condom use there are still barriers to the use of condoms in Jamaica.

Knowledge of HIV transmission and prevention in our study group was generally low as indicated by our low median scores. The HIV/AIDS Behavioral Surveillance Survey, Jamaica 1999-2000 also reported that knowledge of specific aspects of HIV prevention and methods of transmission, particularly regarding ways that HIV cannot be transmitted (such as by mosquito bites or by sharing a meal) needs to be improved [15].

After controlling for other factors, employment was found to be significantly associated with condom use during the last sexual episode. Those who were employed were 2.3 times as likely to have used a condom during their last sexual episode compared to those unemployed. This finding seems to be supported by other studies on condom use which have shown that higher socioeconomic status is associated with increased likelihood of condom use [16]. Employment is often associated with a higher level of education and socioeconomic status. This finding highlights the urgency to re-evaluate current programs related to increasing condom use among socio-economically disadvantaged groups in Jamaica.
In this study, participants with the ability to list the names of STIs, including HIV, and their symptoms were significantly more likely to report condom use during their last sexual episode. Thus, familiarity (probably personal experience) with the harmful effects of STIs seems to be a strong predictor of condom use. Individuals who are unaware of the various STIs and their symptoms often have a lower perception of risk. Some studies have suggested that greater HIV/AIDS knowledge and perception of risk is associated with greater condom use and safer sex practices $[17,18]$. Other studies have associated lower risk perception with higher rates of HIV infection [19]. Hence educating people in Montego Bay, the Parish of St. James, and Jamaica as a whole, about the various STIs and their symptoms may increase risk perception and condom use.

Our study also showed that individuals with multiple sexual partners were less likely to report condom use during their last sexual episode compared to those with one sexual partner. This is of concern since individuals with multiple sexual partners who do not use condoms are at a high risk of contracting STIs. The findings of studies on condom use in relation to number of sexual partners appear to be inconsistent. Some studies suggest that there is greater condom use among individuals with multiple partners [20-22] while others report decreased condom use particularly among women [18] and adolescents [23] with multiple partners. It is also important to note that some investigators have shown that individuals report greater condom use with non-regular sexual partners as compared to regular partners [14]. A possible explanation for 
our finding is that individuals with multiple sexual partners may not perceive the risk of infection and hence do not use condoms. Our study can be construed as a clarion call to programs targeting STI clinic attendees that emphasis should be placed not only on condom use at each sexual episode among those with multiple partners but also on limiting the number of sexual partners.

We also found that participants who belonged to a religious organization were $50 \%$ less likely to report condom use during their last sexual encounter. In view of the fact that an overwhelming majority of study participants (68.2\%) belonged to religious organizations, health policy makers in Jamaica may consider it worthwhile to incorporate religious organizations into current campaigns to augment safer sex through dissemination of information on abstinence and safer sexual practices. Religious groups may oppose condom sales [24] and regard the transmission of STIs/HIV as due to promiscuity and/or homosexuality [25]. In a study conducted in Trinidad, study participants who were living with HIV/AIDS described discriminatory experiences with pastors or congregation members during gatherings for religious services. In this study, members of Christian denominations and other religious groups differed in their positions on condom use. Some accepted condom use in light of the HIV/AIDS epidemic while others disagreed with condom use regarding it as a poor substitute for self control [25].

\section{CONCLUSION}

The main limitation of our study is the sample size. It is possible that there are other factors influencing condom use in this population that were not detected due to the relatively small sample size. Within this limitation, our ability to identify the four factors (employment, high STI knowledge, not having multiple sexual partners and not belonging to a religious organization) as significantly predictive of condom use is clear evidence that these are strong determinants of condom use. For a country with limited resources such as Jamaica, it will be an efficient strategy to focus on these factors as priority areas in the ongoing programs to promote safer sex especially in Montego Bay, the Parish of St. James, and the country as a whole.

\section{ACKNOWLEDGEMENTS}

This research was funded by the Minority International Research Training (MIRT) grant \#T37-TW00077 from the Fogarty International Center, National Institutes of Health, Bethesda, MD, USA and the Western Region Health Authority, Ministry of Health, Jamaica.

\section{REFERENCES}

[1] UNICEF Jamaica Statistics. Available from www.unicef.org/infoby country/jamaica_statistics.html Accessed 12/20/2007

[2] UNAIDS 2006 report on the global AIDS epidemic. A UNAIDS $10^{\text {th }}$ anniversary special edition. Geneva: UNAIDS, 2006.
[3] World Health Organization. Epidemiology Fact Sheets on HIV/AIDS and Sexually Transmitted Infections 2002 Update.

[4] World Health Organization. Epidemiology Fact Sheets on HIV/AIDS and Sexually Transmitted Infections 2000 Update.

[5] Ministry of Health National HIV/STI Control Programme Facts and Figures HIV/AIDS Epidemic Update 2006. Ministry of Health, Jamaica, 2006.

[6] Vickers IE, Alveranga H, Smikle MF. Clinical and epidemiological characteristics of adult and adolescent patients newly diagnosed with the human immunodeficiency virus at a Jamaican clinic for sexually transmitted infections. West Indian Med J 2005; 54: 360-3.

[7] Jamaica's HIV/AIDS/STI National Strategic Plan 2002-2006. Ministry of Health, Jamaica, 2002.

[8] Davis KR, Weller SC. The effectiveness of condoms in reducing heterosexual transmission of HIV. Fam Plann Perspect 1999; 31: 272-9.

[9] Weller S, Davis K. Condom effectiveness in reducing heterosexual HIV transmission. The Cochrane Library, Issue 2. Oxford: Update Software 2003.

[10] United States Department of Health and Human Services (US DHHS). Scientific review panel confirms condoms are effective against HIV/AIDS, but epidemiological studies are insufficient for other STDs. [press release] July 20, 2001. Available at www.hhs. gov/news/press/2001 pre/20010720.html

[11] Stover J, Walker N, Garnett GP, et al. Can we reverse the HIV/AIDS pandemic with an expanded response? Lancet 2002; 360: 73-7.

[12] Figueroa JP. HIV/AIDS in the Caribbean. The need for a more effective public health response. West Indian Med J 2003; 52: 156-8.

[13] Norman LR, Uche C. Prevalence and determinants of sexually transmitted diseases. An analysis of young Jamaican males. Sex Transm Dis 2002; 29: 126-32.

[14] Figueroa JP, Brathwaite AR, Wedderburn M, et al. Is HIV/STD control in Jamaica making a difference? AIDS 1998; 12: S89-S98.

[15] HIV/AIDS Behavioral Surveillance Survey Jamaica 1999- 2000. BSS Round 1 - Final Report.

[16] Norman LR. Predictors of consistent condom use: a hierarchical analysis of adults from Kenya, Tanzania and Trinidad. Int J STD AIDS 2003; 14: 584-90.

[17] Adih WK, Alexander CS. Determinants of condom use among youth in Ghana. J Adolesc Health 1999; 24: 63-72.

[18] MacDonald NE, Wells GA, Fisher WA, et al. High risk STD/HIV behavior among college students. JAMA 1990; 263: 3155-9.

[19] Mbizvo EM, Msuya SE, Hussain A, Chirenje MZ, Stray-Pedersen B. HIV prevalence in Zimbabwean women: 54-67\% knowledge and perceived risk. Int J STD AIDS 2003; 14: 202-7.

[20] Mnyika KS, Klepp K, Kvale G, Ole-King'ori N. Determinants of high-risk sexual behaviour and condom use among adults in the Arusha region, Tanzania. Int J STD AIDS 1997; 8: 176-83.

[21] Ndinya-Achola JO, Ghee AE, Kihara AN, et al. High HIV prevalence, low condom use and gender differences in sexual behaviour among patients with STD-related complaints at a Nairobi primary health care clinic. Int J STD AIDS 1997; 8: 506-14.

[22] Simeon DT, LeFranc E, Bain B, Wyatt GE. Experiences and socialization of Jamaican men with multiple sex partners. West Indian Med J 1999; 48(4): 212-5.

[23] Shafer MA, Boyer CB. Psychosocial and behavioral factors associated with risk of sexually transmitted diseases, including human immunodeficiency virus infection, among urban high school students. J Pediatr 1991; 119: 826-33.

[24] Genrich GL, Brathwaite BA. Response of religious groups to HIV/AIDS as a sexually transmitted infection in Trinidad. BMC Public Health 2005, 5: 121. Available from: http: //www.biomed central.com/1471-2458/5/121

[25] Richards P. Health - Trinidad and Tobago: religious groups oppose condom use sales. 2001. Available from: http: //www.aegis.com/ news.ips/2001/IP010628.html 